\title{
Cost of resistance, expressed as a delayed maturity, detected in the host-parasite system Biomphalaria glabrata/Echinostoma caproni
}

\author{
J ULIETTE LANGAND*†, J OSEPH J OURDANE $\uparrow$, CHRISTINE COUSTAU $\dagger$, BERNARD \\ DELAY $\$$ \& SERGE MORAND $\dagger$ \\ †Laboratoire de Biologie Animale, UMR 5555 (CNRS), Université de Perpignan, 52, avenue de Villeneuve, 66860 \\ Perpignan, France and \$Centre d’Ecologie Fonctionnelle et Evolutive, CNRS, BP 5051, 34033 Montpellier Cedex 1 \\ France
}

\begin{abstract}
Theoretical models have shown that when susceptibility to a parasite is genetically determined, polymorphism with regard to susceptibility can only be maintained by costs associated with resistance. However, an apparent resistance, or nonsusceptibility, may result from a lack of adaptation of the parasite, which does not imply any costs for the host. In this study, we analysed whether susceptibility was genetically determined in the Biomphalaria glabrata/Echinostoma caproni system, and we investigated the existence of costs associated with nonsusceptibility. Results showed that nonsusceptibility of B. glabrata to E. caproni was genetically determined and could be strongly selected for through generations. Furthermore, analysis of age at maturity among offspring segregating for susceptibility revealed that nonsusceptible individuals reached maturity later than susceptible ones. The delay in maturity is statistically significant and reflects a cost associated with resistance.
\end{abstract}

Keywords: Biomphalaria glabrata, cost of resistance, delayed maturity, digenea, Echinostoma caproni, mollusc

\section{Introduction}

In natural populations, individuals susceptible and nonsusceptible to a particular parasite often coexist. Host nonsusceptibility can result from unsuitability or from resistance. An unsuitable host is defined as an individual in which the parasite cannot develop, regardless of the host defences (Lie et al., 1977), whereas a resistant host exhibits adaptive responses, such as a specific immune response which actively kills the parasite. In the absence of information on the precise mechanism underlying the failure of parasitic infection, the broad term of nonsusceptibility is more appropriate. Distinction between the two mechanisms is important for understanding evolution of host-parasite interactions, because costs expressed as a reduced fitness are associated only with resistance and not with unsuitability. The existence of costs of resistance implies that resistance cannot be maintained in the population in the absence of a selective pressure from the parasite.

Several genetic models have attempted to explain the coexistence of susceptible and nonsusceptible individuals in natural populations of hosts. Most of them, including gene-for-gene models (Frank, 1992; Antonovics \& Thrall, 1994) and models with quanti-

*Correspondence. E-mail: digene@univ-perp.fr tative resistance (Frank, 1994a), assume the existence of a cost of resistance to maintain a polymorphism at resistance loci. Other models, such as matching-alleles models, do not assume the existence of such a direct cost associated with resistance to maintain the polymorphism (Frank, 1993, 1994b; Gandon et al., 1996; Morand et al., 1996), but consider that costs are expressed through a susceptibility to other parasite genotypes. Models have shown that low costs of resistance, which cannot easily be measured, can maintain a large polymorphism for susceptibility (Frank, 1993; Antonovics \& Thrall, 1994). Although most genetic models assume the existence of a cost of resistance, only few experimental studies, mainly carried out on plants, have been successful in detecting costs of resistance (Burdon \& Müller, 1987). Costs can be expressed through any fitness trait such as viability, fecundity, growth rate (Sager \& Coley, 1995) or age at maturity (Boots \& Begon, 1993; Alexander \& Antonovics, 1995; Biere \& Antonovics, 1996).

The genetic basis of molluscs' nonsusceptibility to digeneans remains an open question. Under a hypothesis of quantitative inheritance, Grosholz (1994) calculated a heritability of 0.36 for nonsusceptibility in a bivalve mollusc, Transennella tantilla, parasitized by the digenean Parvatrema boreali. Several studies 
have shown the existence of a polymorphism for susceptibility in the Biomphalaria-schistosome system (Sturrock \& Sturrock, 1970; Incani, 1993). Strains of Biomphalaria glabrata were found to exhibit various patterns of susceptibility to Schistosoma mansoni, when studying juveniles, mature adults or senescent adults (Richards, 1975, 1984; Richards \& Minchella, 1987). In this model, the determinism of susceptibility varies with the maturity of the mollusc.

The model Biomphalaria/Echinostoma has hardly been investigated even though it presents some interesting features (Loker \& Adema, 1995). Echinostomes castrate their molluscan hosts more efficiently than schistosomes (Jourdane \& Kulo, 1982). Castration corresponds to the genetic death of a parasitized host. A stronger decrease in fecundity should result in a stronger selection for the genetic resistance in snails. Moreover, Mounkassa \& Jourdane (1990) and Monroy \& Loker (1993) showed that the intensity of the immune response of the snail B. glabrata is higher when it is infected by $E$. caproni or E. paraensei than when it is exposed to $S$. mansoni. The host-parasite system, B. glabrata/E. caproni, with its strongly antagonistic interactions, seems particularly suitable for the detection of costs of resistance.

In the present study, we used laboratory strains of B. glabrata and E. caproni first to analyse the genetic basis of the adult susceptibility and then to investigate the existence of a cost associated with nonsusceptibility. Offspring segregating for susceptibility were used in order to decrease the strain effects. Parasitism acts directly on some fitness traits such as fecundity (parasitic castration) and viability. Because individuals from segregating progeny must be exposed to parasitism to determine whether they are susceptible or not, costs expressed as a decrease in fecundity or viability cannot be directly detected on these individuals. Alternatively, we decided to focus on the potential delay of maturity, because age at maturity is a fitness trait that can be measured before exposing snails to parasites.

\section{Materials and methods}

\section{Studied individuals}

Biomphalaria glabrata snails used in this study were reared in an environmental temperature chamber at $25^{\circ} \mathrm{C}$, on a $12 \mathrm{~L} / 12 \mathrm{D}$ cycle in our laboratory (Théron, 1981). Food consisted of fresh lettuce for adults, and blue-green algae (Nostoc muscorum) for young juveniles. Biomphalaria glabrata is a hermaphroditic snail able to self-fertilize. The strain of E. caproni (Jeyarasasingam et al., 1972) has been maintained for several years in our laboratory. Echinostoma caproni is a hermaphroditic parasite with an indirect life cycle involving three hosts. Asexual multiplication occurs in the first intermediate snail host, which is castrated by the larval stage (rediae) of the parasite. Echinostoma caproni is much less pathogenic for its second intermediate host (usually a mollusc) and its definitive host (mammals and birds) for which it also usually lacks specificity (Huffman \& Fried, 1990).

\section{Experimental infection}

Susceptibility was assessed after exposing snails to the infective larval stage (miracidium) of E. caproni. Within the first two weeks following the first onset, snails $(5-10 \mathrm{~mm})$ were individually exposed to 10 miracidia in flasks containing $5 \mathrm{~mL}$ water, for 15-18 h. To control for parasite infectivity, six to eight snails from a susceptible line were exposed simultaneously. Snails were dissected under a binocular microscope at 20-35 days post exposure and checked for infection. If more than two snails of the control group were noninfected, all molluscs of the test group were re-exposed to a new batch of parasites. Molluscs were considered susceptible or nonsusceptible according to the presence of $E$. caproni rediae in the digestive gland-gonad complex of the snail.

Onset of egg laying was used as the criterion for the age at maturity. Egg masses were collected during one week before parasite exposure.

\section{Genetic basis of susceptibility}

A large number of juvenile snails were isolated and kept separately in individual containers, until they reached sexual maturity and produced offspring by self-fertilization. Mature snails were then tested for their susceptibility to E. caproni. The offspring of 18 individuals, nine susceptible and nine nonsusceptible, were maintained until sexual maturity, and then tested for adult susceptibility to E. caproni. A Mann-Whitney test was used to compare the susceptibility of the progeny of both susceptible and nonsusceptible individuals.

An artificial selection experiment was carried out using these offspring during two to three generations to select for susceptibility and nonsusceptibility. A first generation was obtained by self-fertilization of single individuals (susceptible or nonsusceptible). However, in some lines, we were not able to obtain such offspring because of selfing depression (as 
defined by Jarne et al., 1990) problems. Consequently, we continued this selection experiment by outcrossing a small number of siblings (five to 20) of the desired phenotype. Four lines: two susceptible (S1 and S2) and two nonsusceptible (R1 and R2) were thus obtained.

\section{Detection of a cost associated with nonsusceptibility}

Age at maturity was analysed in individuals segregating for susceptibility, obtained according to the scheme of Fig. 1. Nine crosses between nonsusceptible and susceptible individuals from the selected strains (R1, R2, S1 and S2) were obtained $\left(\mathrm{F}_{0}\right)$. Among the offspring of these crosses, 27 self-fertilizing hybrids $\left(\mathrm{F}_{1}\right)$ were isolated. Their progeny was composed of a mixture of nonsusceptible and susceptible individuals. Age at maturity and susceptibility were recorded for $944 \mathrm{~F}_{2}$ individuals, 322 susceptible and 622 nonsusceptible ones. Lineage, susceptibility and age at maturity were recorded for each individual.

The effects of susceptibility and family on the age of snails at maturity were assessed using a two-way analysis of variance. Age at maturity was logtransformed in order to normalize residuals.

\section{Results}

\section{Genetic basis of susceptibility}

The offspring of the susceptible $B$. glabrata were susceptible at a rate of $50-100$ per cent (81 per cent on average). The susceptibility of the offspring from

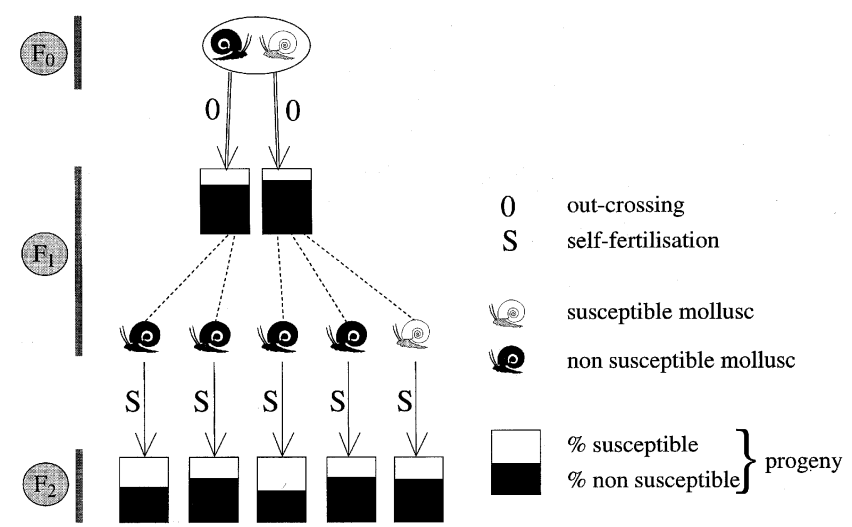

Fig. 1 Simplified diagram of the design to obtain offspring of Biomphalaria glabrata segregating for susceptibility. Crosses were carried out between one individual from a susceptible line and one individual from a nonsusceptible line $\left(F_{0}\right)$. Offspring from these crosses $\left(F_{1}\right)$ were isolated. They produced, by self-fertilization, offspring segregating for susceptibility $\left(\mathrm{F}_{2}\right)$. the nonsusceptible $B$. glabrata ranged from 0 to 79 per cent (25 per cent on average) (Fig. 2).

A Mann-Whitney test showed that the difference in susceptibility between offspring of susceptible and nonsusceptible snails was significant $(P=0.013)$ and suggested that susceptibility had a genetic origin.

This result was confirmed when further selection for susceptibility/nonsusceptibility was carried out, because the differences between susceptible and nonsusceptible selected lines were highly significant (Table 1).

\section{Cost associated with nonsusceptibility}

Although age at maturity of the $\mathrm{F}_{2}$ molluscs ranged from 7 to 21 weeks, the results of the ANOVA (Table 2) showed a significant effect of the family (offspring from one couple) on the age at maturity $(P<0.0001)$, which was 106.5 days for susceptible and 110.7 days for nonsusceptible snails. This difference is highly significant $(P<0.0096)$. Furthermore, there is no interaction between susceptibility and family effects $(P=0.119)$ showing that the effect of nonsusceptibility on maturity is consistent among families.

\section{Discussion}

The genetic basis of susceptibility/nonsusceptibility of molluscs to digenean trematodes has mainly been studied using the host-parasite system B. glabrata-S. mansoni (Richards et al., 1992). In our study, we investigated for the first time the determination of $B$. glabrata susceptibility to E. caproni. The analysis of the susceptibility of offspring from either susceptible or nonsusceptible adult snails showed that susceptibility is genetically determined. In addition, we were able to select two susceptible and two nonsusceptible strains showing, respectively, 4 per cent, 7 per cent, 77 per cent and 90 per cent nonsusceptibility after only three to four generations of selection.

Few studies have suggested the existence of costs of resistance in mollusc-digenean systems and they were all carried out on the B. glabrata-S. mansoni system. Minchella \& Loverde (1983) compared the relative success of two mollusc strains, an albino nonsusceptible and a black-eyed susceptible, and showed that the black-eyed susceptible individuals were more fecund when the two strains were reared together in the presence of the parasite. However, it is difficult to determine whether the difference in fitness between the two strains was linked to differences in susceptibility, in pigmentation or in other 
Fig. 2 Range of adult susceptibility and nonsusceptibility within selffertilizing progenies from susceptible and nonsusceptible parents of Biomphalaria glabrata.

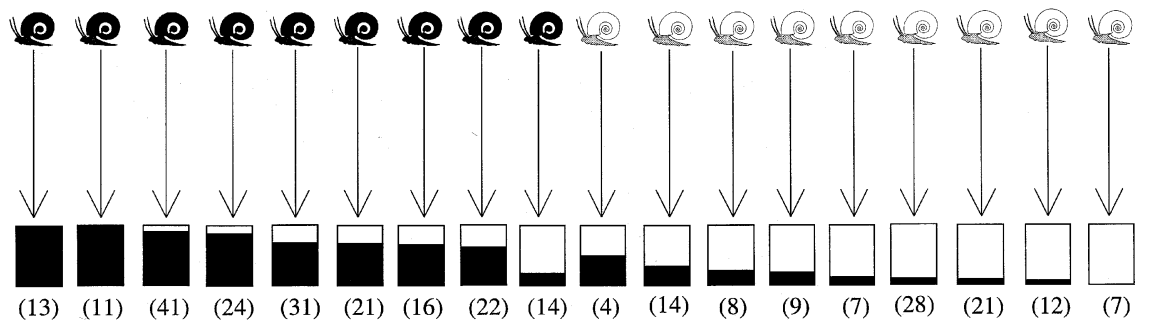

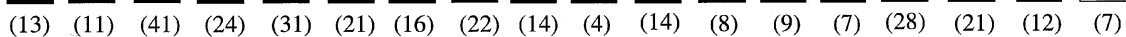

$\square \begin{aligned} & \% \text { susceptible } \\ & \% \text { non susceptible }\end{aligned}$
$\begin{aligned} & \text { number exposed } \\ & (22)\end{aligned}$ progeny characters differentiating the two strains. Similarly, Mulvey \& Woodruff (1985), also using B. glabrata from the same source (NIH), suggested that albino snails had a lower viability. Vianey-Liaud (1997) demonstrated, using two strains of albino B. glabrata (Brazil and Puerto Rico) and one pigmented strain (Brazil), that albino snails preferentially used the allosperm from the pigmented partner. There could therefore be an under-evaluation of the fecundity of albino nonsusceptible snails in the study of Minchella \& Loverde (1983). Cooper et al. (1994) suggested that $B$. glabrata nonsusceptible to $S$. mansoni might be less efficient when selfing than susceptible snails. However, Cousin et al. (1995) showed that great abnormalities exist in the albumen gland of the strain, LAC-Line, used by Cooper et al. (1994), and this gland is known to provide a major source of nourishment for the fertilized eggs

Table 1 Percentage of nonsusceptible individuals of Biomphalaria glabrata in the four selected lines

Percentage of nonsusceptibility

Lines selected (uninfected molluscs/exposed molluscs)

\begin{tabular}{lc}
\hline R1 & $77 \%(=113 / 147)$ \\
R2 & $90 \%(=173 / 192)$ \\
S1 & $4 \%(=14 / 315)$ \\
S2 & $7 \%(=22 / 313)$ \\
\hline
\end{tabular}

Table 2 Effects of susceptibility and family on the age of Biomphalaria glabrata at maturity (ANOVA)

\begin{tabular}{lcccl}
\hline Independent variables & d.f. & Mean squares & $F$ & $P$ \\
\hline Family & 8 & 2531 & 5.050 & $0.0001^{*}$ \\
Susceptibility & 1 & 3539 & 7.063 & $0.0080^{*}$ \\
Family $\times$ susceptibility & 8 & 824 & 1.644 & 0.1085 \\
\hline
\end{tabular}

Dependent variable: age at maturity.

*Highly significant, $P<0.01$.

(C) The Genetical Society of Great Britain, Heredity, 80, 320-325.
(Goudsmit, 1976). Such abnormalities may result from the inbreeding of this stock, and their direct link with nonsusceptibility remains to be ascertained.

In contrast to these studies, the susceptible and nonsusceptible $B$. glabrata we used derived from a single strain and have not been subjected to years of selection and possible genetic drift as a consequence of small laboratory population size or concomitant selection of genes unrelated to susceptibility. In addition, the segregation obtained in the progeny of self-fertilizing hybrids should eliminate most of the strain effects. Genes which could influence age at maturity have segregated in this progeny and should not affect our result unless they are also linked to gene(s) for nonsusceptibility. However, because the effect of nonsusceptibility on the age at maturity does not differ significantly according to the family, such linked genes cannot represent a significant bias.

In our study, the analysis of age at maturity showed that nonsusceptible molluscs mature significantly later than susceptible ones. One explanation would be that nonsusceptibility increases with host age. In this case, snails that mature later would have been tested for susceptibility at a greater age and would have been less susceptible. However, this would mean that the increase in nonsusceptibility is very fast because it could be detected for individuals differing by only 4 days on average. Moreover, a large decrease in susceptibility should be detected for old individuals, which was not the case. Individuals from susceptible strains tested at older ages $(13-16 \mathrm{~mm})$ displayed no weaker susceptibilities than that reported in the present study (C. Coustau, personal communication). The most likely explanation is that the delayed maturity observed in nonsusceptible snails is an expression of a cost of resistance.

At the immunological level, the cost could be associated with a quantitative difference, such as a higher number of haemocytes. In the case of B. glab- 
rata and $S$. mansoni, it has been reported that two susceptible strains had fewer circulating haemocytes than a resistant strain (Coustau \& Yoshino, 1994a). However, resistance may also be related to qualitative changes in soluble plasma factors (Fryer \& Bayne, 1989) or haemocyte components (Yoshino \& Granath, 1985; Coustau \& Yoshino, 1994b).

The existence of a cost of resistance has a practical impact on the maintenance of resistant strains in the laboratory. Indeed, if they are not totally homozygous for resistance, the selective pressure on the strains has to be maintained. Lie \& Heyneman (1979) have observed variable losses (0-50 per cent) of nonsusceptibility to $S$. mansoni in three B. glabrata strains derived from one highly nonsusceptible strain. Snails were maintained over several years without selection for nonsusceptibility to parasitism. This suggests that the cost of nonsusceptibility, and mechanisms of nonsusceptibility, were different for these three strains.

Although many studies have focused on costs of resistance in plant/pathogen systems, such costs are difficult to detect (Antonovics \& Thrall, 1994). Thus, the existence of a cost expressed by a delayed maturity of 4 per cent in the B. glabrata-E. caproni system is particularly promising. The $B$. glabrata-E. caproni model is an extreme host-parasite model because the fitness of the parasitized mollusc decreases to zero. Our strain of E. caproni completely destroys the reproductive gland of our strain of $B$. glabrata and no single snail was observed to outlive this parasite. Such a system is not likely to allow the development of tolerance. This alternative strategy to resistance has been shown in plant-fungi systems (Simms \& Triplett, 1994). However, it would be possible for tolerance to evolve in other snail-digenean systems where reduction of fecundity is not complete, such as some mollusc-schistosome systems (Fryer et al., 1990). When tolerance exists, the selective pressure for resistance may be reduced. The characterization of resistance and costs of resistance in a host-parasite system where castration occurs can be particularly appropriate for understanding the selective pressures of parasitism.

\section{Acknow ledgements}

We thank P. Jarne, I. Olivieri, C. Combes, G. Sorci and $\mathrm{Y}$. Michalakis for critically reading the manuscript. This work was financed by CNRS (Science de la vie). J. Langand was supported by a fellowship from the French 'Ministère de la Recherche et de l'Enseignement Supérieur'.

\section{References}

AlEXANDER, H. M. AND ANTONOVICS, J. 1995. Spread of anther-smut disease (Ustilago violacea) and character correlations in a genetically variable experimental population of Silene alba. J. Ecol., 83, 783-794.

ANTONOVICS, J. AND THRALL, P. H. 1994. The cost of resistance and the maintenance of genetic polymorphism in host-pathogen systems. Proc. R. Soc. B, 257, 105-110.

BIERE, A. AND ANTONOvics, J. 1996. Sex-specific costs of resistance to the fungal pathogen Ustilago violacea (Microbotryum violaceum) in Silene alba. Evolution, 50, 1098-1110.

BOOTS, M. AND BEGON, M. 1993. Trade-off with resistance to granulosis virus in the Indian meal moth, examined by a laboratory evolution experiment. Funct. Ecol., 7, 528-534.

BURdon, J. J. AND MÜller, w. J. 1987. Measuring the cost of resistance to Puccinia coronata Cda in Avena fatua L. J. Appl. Ecol., 24, 191-200.

COOPER, L. A., RICHARDS, S. C., LEWIS, F. A. AND MINCHELlA, D. J. 1994. Schistosoma mansoni relationship between low fecundity and reduced susceptibility to parasite infection in the snail Biomphalaria glabrata. Exp. Parasitol., 79, 21-28.

COUSIN, C., OFORI, K., ACHOLONU, S., MILlER, A., RICHARDS, C., LEWIS, F. AND KNIGHT, M. 1995. Schistosoma mansoni: changes in the albumen gland of Biomphalaria glabrata snails selected for non-susceptibility to the parasite. $J$. Parasitol., 81, 905-911.

COUStau, C. AND yoshino, T. P. 1994a. Surface membrane polypeptides associated with hemocytes from Schistosoma mansoni-susceptible and -resistant strains of Biomphalaria glabrata (Gastropoda). J. Invert. Pathol., 63, 82-89.

COUstau, C. AND Yoshino, т. P. 1994b. Schistosoma mansoni: Modulation of hemocyte surface polypeptides detected in individual snails, Biomphalaria glabrata, following larval exposure. Exp. Parasitol., 79, 1-10.

FRANK, S. A. 1992. Models of plant-pathogen coevolution. Trends Genet., 8, 213-219.

FRANK, S. A. 1993. Specificity vs. detectable polymorphism in host-parasite genetics. Proc. R. Soc. B, 254, 191-197.

FRANK, s. A. 1994a. Coevolutionary genetics of hosts and parasites with quantitative inheritance. Evol. Ecol., 8, 74-94.

FRANK, S. A. 1994b. Recognition and polymorphism in host-parasite genetics. Phil. Trans. R. Soc. B, 346, 283-293.

FRYER, S. E. AND BAYNE, C. J. 1989. Opsonization of yeast by the plasma of Biomphalaria glabrata (Gastropoda): a strain-specific, time dependent process. Parasite Immunol., 11, 269-278.

FRYER, S. E., OSWALD, R. C., PROBERT, A. J. AND RUNHAM, N. W. 1990. The effect of Schistosoma haematobium infection on the growth and fecundity of three sympatric species of bulinid snails. J. Parasitol., 76, 557-563.

GANDON, S., CAPOWIEZ, Y., DUBOIS, Y., MICHALAKIS, Y. AND OLIVIERI, I. 1996. Local adaptation and gene-for-gene

(c) The Genetical Society of Great Britain, Heredity, 80, 320-325. 
coevolution in a metapopulation model. Proc. $R$. Soc. B., 263, 1003-1009.

GOUDSMIT, E. M. 1976. Galactogen catabolism by embryos of freshwater snails Bulimnaea megasoma and Lymnaea stagnalis. Comp. Biochem. Physiol., 53, 539-542.

Grosholz, E. D. 1994. The effect of host genotype and spatial distribution on digene parasitism in a bivalve population. Evolution, 48, 1514-1524.

HUFFMAN, J. E. AND FRIED, B. 1990. Echinostoma and echinostomiasis. Adv. Parasitol., 29, 215-269.

INCANI, R. N. 1993. Compatibility of one Brazilian and two Venezuelan strains of Schistosoma mansoni with various strains of Biomphalaria glabrata. Parasitol. Res., 79, $508-511$.

JARNE, P., FinOT, L., DElAy, B. AND THALER, L. 1990. Selffertilisation in the hermaphroditic freshwater snail Bulinus globosus. Evolution, 45, 1136-1146.

JEYARASASINGAM, U., HEYNEMAN, D., HOK-KAN, L. AND NOSHY, M. 1972. Life cycle of a new echinosotome from Egypt, Echinostoma liei sp. nov. (Trematoda: Echinostomatidae). Parasitology, 65, 2303-2322.

JOURDANE, J. AND KUlO, S. D. 1982. Pespectives d'utilisation de Echinostoma togoensis Jourdane and Kulo, 1981 dans le contrôle biologique de la bilharziose intestinale en Afrique. Ann. Parasitol. (Paris), 57, 443-451.

LIE, K. J. AND HEYNEMAN, D. 1979. Specificity of natural resistance to digene infection in Biomphalaria glabrata. Int. J. Parasitol., 9, 529-531.

LIE, K. J., HEYNEMAN, D. AND RICHARDS, C. S. 1977. Schistosoma mansoni: temporary reduction of natural resistance in Biomphalaria glabrata induced by irradiated miracidia of Echinostoma paraensei. Exp. Parasitol., 43, 54-62.

LOKER, E. S. AND ADEMA, C. M. 1995. Schistosomes, echinostomes and snails: comparative immunobiology. Parasitol. Today, 11, 120-124.

MINCHELlA, D. J. AND LOVERDE, P. T. 1983. Laboratory comparison of the relative success of Biomphalaria glabrata stocks which are susceptible and non-susceptible to infection with Schistosoma mansoni. Parasitology, 86, $335-344$.

MONROY, F. P. AND LOKER, E. S. 1993. Production of heterogeneous carbohydrate-binding proteins by the host snail Biomphalaria glabrata following the exposure to Echinostoma paraensei and Schistosoma mansoni. J. Parasitol., 79, 416-423.

MORAND, S., MANNING, S. D. AND WOOLhOUSE, M. E. J. 1996. Parasite-host coevolution and geographic patterns of parasite infectivity and host susceptibility. Proc. $R$. Soc. $B, \mathbf{2 6 3}, 119-128$.

MOUNKASSA, J. B. AND JOURDANE, J. 1990. Dynamics of the leukocytic response of Biomphalaria glabrata during the larval development of Schistosoma mansoni and Echinostoma liei. J. Invert. Pathol., 55, 306-311.

MULVEY, M. AND WOODRUFF, D. S. 1985. Genetics of Biomphalaria glabrata: linkage analysis of genes for pigmentation, enzymes, and resistance to infection with Schistosoma mansoni. Biochem. Genet., 22, 877-889.

RICHARDS, C. S. 1975. Genetic factors in susceptibility of Biomphalaria glabrata for different strains of Schisosoma mansoni. Parasitology, 70, 231-241.

RICHARDS, C. S. 1984. Influence of snail age on genetic variations in susceptibility of Biomphalaria glabrata for infection with Schistosoma mansoni. Malacologia, 25, 493-502.

RICHARDS, C. S. AND MINCHELlA, D. J. 1987. Transient non-susceptibility to Schistosoma mansoni associated with atrial amoebocytic accumulations in the snail host Biomphalaria glabrata. Parasitology, 95, 499-505.

RICHARDS, C. S., KNIGHT, M. AND LEWIS, F. A. 1992. Genetics of Biomphalaria glabrata and its effect on the outcome of Schistosoma mansoni infection. Parasitol. Today, 8, 171-174.

SAGER, C. L. AND COLEY, P. D. 1995. Benefits and costs of defense in a neotropical shrub. Ecology, 76, 1835-1843.

SIMMS, E. L. AND TRIPLETT, J. 1994. Costs and benefits of plant responses to disease: resistance and tolerance. Evolution, 48, 1973-1985.

STURROCK, R. F. AND STURROCK, B. M. 1970. Observations on the susceptibility to Schistosoma mansoni from St. Lucia of several Caribbean strains of snails of the genus Biomphalaria. W. I. Med. J., 19, 10-13.

THÉron, A. 1981. Dynamics of larval populations of Schistosoma mansoni in Biomphalaria glabrata. I Rhythmic production of cercariae in monomiracidial infections. Ann. Trop. Med. Parasitol., 75, 71-77.

VIANEY-LIAUD, M. 1997. Bias in the production of heterozygous pigmented embryos from successively mated Biomphalaria glabrata (Gastropoda: Planorbidae) albino snails. Malacologia Review, in press.

yoshino, T. P. AND GRANATH, w. O. 1985. Surface antigens of Biomphalaria glabrata (Gastropoda) hemocytes: functional heterogeneity in cell sub-populations recognized by a monoclonal antibody. J. Invert. Pathol., 45, $174-186$. 